\title{
PARAMETRIC SENSITIVITY OF A CFD MODEL CONCERNING THE HYDRODYNAMICS OF TRICKLE-BED REACTOR (TBR)
}

\author{
Daniel Janecki ${ }^{1}$, Andrzej Burghardt ${ }^{2}$, Grażyna Bartelmus ${ }^{2 *}$ \\ ${ }^{1}$ Department of Process Engineering, University of Opole, ul. Dmowskiego 7-9, 45-365 Opole, \\ Poland \\ ${ }^{2}$ Institute of Chemical Engineering, Polish Academy of Sciences, ul. Bałtycka 5, 44-100 Gliwice, \\ Poland
}

\section{Dedicated to Prof. Ryszard Pohorecki on the occasion of his 80th birthday}

\begin{abstract}
The aim of the present study was to investigate the sensitivity of a multiphase Eulerian CFD model with respect to relations defining drag forces between phases. The mean relative error as well as standard deviation of experimental and computed values of pressure gradient and average liquid holdup were used as validation criteria of the model. Comparative basis for simulations was our own data-base obtained in experiments carried out in a TBR operating at a co-current downward gas and liquid flow. Estimated errors showed that the classical equations of Attou et al. (1999) defining the friction factors $F_{j k}$ approximate experimental values of hydrodynamic parameters with the best agreement. Taking this into account one can recommend to apply chosen equations in the momentum balances of TBR.
\end{abstract}

Keywords: hydrodynamics, trickle-flow regime, pressure gradient, liquid holdup, phases interaction, CFD

\section{INTRODUCTION}

Three-phase reactors in which liquid and gas phases flow cocurrently downwards through a fixed bed of catalyst particles are commonly called "trickle-bed reactors (TBR)". Reactors of this type form a very important group of apparatuses used in quite a few branches of chemical industry, mainly in the processes of treating various fractions of crude oil with hydrogen. The main advantage of columns operating in the cocurrent downflow of two phases is the possibility of using high flow rates without causing flooding in the column - a phenomenon which considerably limits the operating range of the countercurrent flow. Therefore, these apparatuses are used extensively in those branches of industry which process high streams of substrates (mainly in the petrochemical and petroleum industries).

Depending on the flow rates of two phases, their physicochemical properties and the geometry and size of the packing, various hydrodynamic regimes can be observed. Industry processes are generally carried out in the gas continuous flow regime (GCF). However, for example, in hydrodesulphurisation process pulsing flow is more and more often used. As the range of TBRs applications is immense, extensive research has been carried out in recent years in order to extend our knowledge about the mechanism of hydrodynamic processes taking place in these reactors. A fundamental understanding of the hydrodynamics of trickle bed reactors is indispensable for their design, operation and scale - up. 
The base hydrodynamic parameters are pressure gradient and liquid saturation. Pressure gradient is related to the mechanical energy dissipation due to the two - phase flow through the fixed bed. Liquid saturation is related to other important hydrodynamic parameters such pressure drop, external wetting of catalyst particles, EBRT (empty bed residence time) of the liquid phase in a reactor and mass and heat transfer phenomena (Attou et al., 1999). In the literature, a large number of studies have been presented in which, for various experimental systems (Charpentier and Favier, 1975; Midoux et al., 1976; Mills and Dudukovic, 1981; Sai and Varma, 1985; Specchia and Baldi, 1977), specific ranges of operating conditions (Burghardt et al., 2002, 2005; Szlemp et al., 2001), atmospheric and elevated pressure (Al-Dahhan et al., 1997; Larachi et al. 1991; Wammes et al., 1991), the mentioned above parameters have been determined experimentally. Correlations which were established on the basis of experimental data were summarised by Soroha and Nigam (1996) and Al-Dahhan et al. (1997). Experimental results clearly indicate that fluid dynamics has to be introduced into the quantitative description of the process. The momentum balance can be used to estimate the dynamic parameters of the fluid flow, i.e. a velocity profile of two phases, a hold-up profile and a pressure gradient in the reactor. These are strictly connected with the phenomena of mass and energy transport between phases, and thus indirectly influence the yield of a chemical process (Burghardt, 2014).

Among these studies there are three one-dimensional two - phase models which enable the prediction of pressure gradient and liquid saturation in TBR and provide formulae for coefficients which determine interphase momentum exchange. These include the relative permeability model of Saez and Carbonell (1985), the single slit model of Holub et al. (1992), and the two-fluid phase interaction model of Attou et al. (1999). The form of the relationships which define the interaction forces between phases has been developed from Ergun equations. The relative permeability model as well as the slit model neglect the interphase force between the gas and liquid phases, thus assuming zero drag force at the gas and liquid interface. However, experimental studies showed (Wammes et al. 1991; Al-Dahhan et al. 1997; Janecki et al., 2014) that the gas flow has a considerable influence on the hydrodynamics of a trickle-bed reactor, especially at high operating pressures. Accordingly, interactions between the gas and liquid phases are not negligible with regard to other momentum transfer mechanisms. So, only the two - fluid phase interaction model of Attou et al. (2000) provides formulae for coefficients of interphase momentum exchange which determine all the interaction forces in a gas-liquid-solid particles system. The equations proposed by Attou et al. (2000) are presented in the next section.

Currently, Eulerian computational fluid dynamics modelling (CFD) is employed as an important tool for performance assessment, development, and scale-up of TBRs (Kuzeljevic and Dudukovic, 2012). Governing equations of the Eulerian CFD model are the volume averaged mass and momentum conservation equations. Although the CFD model is based on fundamental principles, some empirical relations must be implemented into the momentum balance in order to ensure a proper description of the dynamics of very complex three-phase system in an intricate geometrical structure. These empirical relations determine the interactions between the phases (drag forces), the capillary pressure, the wetting efficiency of the pellet's surface as well as axial and radial profiles of the porosity and are usually taken from the literature.

In our previous paper (Janecki et al., 2014), the sensitivity of a CFD model with respect to the following relations and constants was analysed:

- the axial and radial porosity profiles in the bed,

- the values of Ergun constants.

The main goal of this study was to compare experimental and computational results obtained for different forms of equations defining drag forces between the phases based on our own experimental results. The choice of appropriate equations defining the drag forces is a very significant element of uncertainty in the modelling of processes in a TBR. These forces are considerable and are dominating in the momentum balance equations. 
As the pressure gradient and the average holdup are the two main hydrodynamic parameters, these quantities have been chosen for comparison. The mean relative error as well as the standard deviation of experimental and computed values of the parameters mentioned above were used as the validation criteria of the model.

\section{MODEL EQUATIONS}

The volume-averaged equations for each flowing phase, expressed by means of volume fractions occupied by every phase and their velocities, can be written as:

- continuity equation:

$$
\frac{\partial}{\partial t}\left(\alpha_{k} \rho_{k}\right)+\nabla \cdot\left(\alpha_{k} \rho_{k} \vec{u}_{k}\right)=0 ; \quad k=L, g
$$

- momentum balance equation:

$$
\frac{\partial}{\partial t}\left(\alpha_{k} \rho_{k} \vec{u}_{k}\right)+\nabla \cdot\left(\alpha_{k} \rho_{k} \vec{u}_{k} \vec{u}_{k}\right)=-\alpha_{k} \nabla p+\nabla \cdot \alpha_{k} \overline{\bar{\tau}}_{k}+\alpha_{k} \rho_{k} \vec{g}+\sum_{j=1}^{n} F_{j k}\left(\vec{u}_{j}-\vec{u}_{k}\right) ; \quad k=L, g
$$

where the viscous stress tensor is given by:

$$
\overline{\bar{\tau}}_{k}=\eta_{k}\left(\nabla \vec{u}+\nabla \vec{u}^{T}\right)
$$

In the calculations, gas was treated as the primary phase, whereas liquid and solid as the secondary phases.

A two-dimensional (2D) axi-symmetric domain based on a cylindrical coordinate system was applied, which implied the following boundary conditions: in the axis - symmetry, at the wall no-slip condition for both fluids, at the inlet - a flat velocity profiles and atmospheric pressure at the outlet. Experimental values of gas $\left(u_{g}\right)$ and liquid $\left(u_{L}\right)$ velocities and mean volume fraction of the liquid phase were used as initial conditions. Velocity of the solid phase was assumed to be zero.

Unsteady state simulations were performed with the time step of $0.01 \mathrm{~s}$. The final cell size was established in preliminary calculations which determined the required number of cells as grid independent results (7700 cells).

As analysis of the order of magnitude indicated (Janecki et al., 2014), the capillary forces are small in comparison to the magnitude of interphase drag forces and can be neglected in pressure gradient and liquid holdup simulations in a fully established steady-state flow as well as for a prewetted bed (Jiang et al., 2001).

The selection of appropriate relations defining interphase actions in a multiphase system is crucial for accurate modelling of TBR processes. Therefore, numerous authors aiming at the best approximation of experimentally obtained hydrodynamic parameters (pressure drop and liquid holdup) modified and compiled the relationships of friction forces taken from the three models cited above, but mainly from the model of Attou at al. (1999), and introduced them into the macroscopic averaged momentum balance equation.

The exchange coefficients $F_{j k}$ defined by the equation proposed by Attou et al. (1999) are presented below: 
- gas-liquid momentum exchange coefficient:

$$
F_{g L}=A_{g}\left(\frac{\alpha_{S}}{1-\alpha_{g}}\right)^{2 / 3}+B_{g}\left(\frac{\alpha_{S}}{1-\alpha_{g}}\right)^{1 / 3}\left|u_{g}-u_{L}\right|
$$

- gas- solid momentum exhange coefficient:

$$
F_{g S}=A_{g}\left(\frac{\alpha_{S}}{1-\alpha_{g}}\right)^{2 / 3}+B_{g}\left(\frac{\alpha_{S}}{1-\alpha_{g}}\right)^{1 / 3}\left|u_{g}\right|
$$

- liquid-solid momentum exhange coefficient:

$$
F_{L S}=\left(1-\alpha_{S}\right)\left(A_{L}+B_{L}\left|u_{L}\right|\right)
$$

The forms of friction coefficients presented above were used in calculations by Hamidipour et al. (2013) and Janecki et al. (2014). Similar equations were chosen for $F_{g L}$ and $F_{g S}$ by Gunjal et al. (2005, 2007), Lappalainen et al. (2009) and Kuzeljevic et al. (2012). The relationship describing $F_{L S}$ was slightly modified, (the right - hand side of Eq. (16) is multiplied by $\alpha_{L}$ instead of $\varepsilon$ ). Jiang et al. (2002 a,b) tested three sets of relations defining $F_{j k}$ values. These were: modified equations developed by Attou et al.(1999) (Eqs 17-19), equations of Holub et al. (1992) for $F_{g S}$ and $F_{L S}$ and, additionally, a modified equation of Attou et al. (1999) for $F_{g L}$ (Eqns 20-22) and modified equations developed by Saez and Carbonell (1985) for $F_{g S}$ and $F_{L S}$ and, additionally, a modified equation of Attou et al. (1999) for $F_{g L}$ (Eqs. 23-25).

Atta et al. (2007 a,b, 2010 a,b) tested relative permeability model developed by Saez and Carbonell (1985). The authors modified the Ergun equation for the single-phase flow pressure drop to calculate the two - phase flow pressure drop by introducing special parameters, known as permeability coefficients. Unfortunately, the relative permeability model does not provide a relationship defining the drag force at the gas-liquid interface in an explicit form. A set of equations tested by Atta et al. (2007a, b; 2010a, b) is presented in Table 1 (Eqs. 26-27).

The tested relations describing the interaction forces between the phases were transformed to obtain a unified form. So, in these equations, which were put together in Table 1 and compared in Fig.1:

$$
\begin{gathered}
A_{g}=E_{1} \mu_{g} \frac{\left(1-\alpha_{g}\right)^{2}}{\alpha_{g} d_{p}^{2}} \\
B_{g}=E_{2} \rho_{g} \frac{1-\alpha_{g}}{d_{p}} \\
A_{L}=E_{1} \mu_{L} \frac{\alpha_{S}^{2}}{\alpha_{L}^{2} d_{p}^{2}} \\
B_{L}=E_{2} \rho_{L} \frac{\alpha_{S}}{\alpha_{L} d_{p}}
\end{gathered}
$$


Table 1. Equations of interaction forces tested in simulations

\begin{tabular}{|c|c|c|c|}
\hline Case & Exchange coefficients $F_{j k}$ & & References \\
\hline I & $\begin{array}{c}F_{g L}=A_{g}\left(\frac{\alpha_{S}}{1-\alpha_{g}}\right)+B_{g}\left(\frac{\alpha_{S}}{1-\alpha_{g}}\right)\left(u_{g}-u_{L}\right) \\
F_{g S}=A_{g}\left(\frac{\alpha_{S}}{1-\alpha_{g}}\right)^{2 / 3}+B_{g}\left(\frac{\alpha_{S}}{1-\alpha_{g}}\right)^{1 / 3} u_{g} \\
F_{L S}=\left(1-\alpha_{S}\right)\left(A_{L}+B_{L} u_{L}\right)\end{array}$ & (12) & $\begin{array}{l}\text { Hamidipour et al. } \\
\text { (2013) } \\
\text { Janecki et al. (2014) }\end{array}$ \\
\hline II & $\begin{array}{c}F_{g L}=A_{g}\left(\frac{\alpha_{S}}{1-\alpha_{g}}\right)^{2 / 3}+B_{g}\left(\frac{\alpha_{S}}{1-\alpha_{g}}\right)^{1 / 3}\left(u_{g}-u_{L}\right) \\
F_{g S}=A_{g}\left(\frac{\alpha_{S}}{1-\alpha_{g}}\right)^{2 / 3}+B_{g}\left(\frac{\alpha_{S}}{1-\alpha_{g}}\right)^{1 / 3} u_{g} \\
F_{L S}=\alpha_{L}\left(A_{L}+B_{L} u_{L}\right)\end{array}$ & $\begin{array}{l}(14) \\
(15) \\
(16)\end{array}$ & $\begin{array}{l}\text { Gunjal et al. (2005) } \\
\text { Gunjal and Ranade } \\
(2007) \\
\text { Lappalainen et al. } \\
\text { (2009) } \\
\text { Kuzeljevic and } \\
\text { Dudukovic (2012) }\end{array}$ \\
\hline III & $\begin{array}{c}F_{g L}=\frac{\alpha_{g}}{\left(1-\alpha_{S}\right)}\left[A_{g}\left(\frac{\alpha_{S}}{1-\alpha_{g}}\right)^{2 / 3}+B_{g}\left(\frac{\alpha_{S}}{1-\alpha_{g}}\right)^{1 / 3}\left(u_{g}-u_{L}\right)\right] \\
F_{g S}=\frac{\alpha_{g}}{\left(1-\alpha_{S}\right)}\left[A_{g}\left(\frac{\alpha_{S}}{1-\alpha_{g}}\right)^{2 / 3}+B_{g}\left(\frac{\alpha_{S}}{1-\alpha_{g}}\right)^{1 / 3} u_{g}\right] \\
F_{L S}=\alpha_{L}\left(A_{L}+B_{L} u_{L}\right)\end{array}$ & $\begin{array}{l}(17) \\
(18) \\
(19)\end{array}$ & $\begin{array}{l}\text { Jiang et al. } \\
(2002 a, b)\end{array}$ \\
\hline IV & $\begin{array}{c}F_{g L}=\frac{\alpha_{g}}{\left(1-\alpha_{S}\right)}\left[A_{g}\left(\frac{\alpha_{S}}{1-\alpha_{g}}\right)^{2 / 3}+B_{g}\left(\frac{\alpha_{S}}{1-\alpha_{g}}\right)^{1 / 3}\left(u_{g}-u_{L}\right)\right] \\
F_{g S}=\frac{\alpha_{S}}{1-\alpha_{g}}\left[A_{g}\left(\frac{\alpha_{S}}{1-\alpha_{g}}\right)+B_{g} u_{g}\right] \\
F_{L S}=\alpha_{L}\left(A_{L}+B_{L} u_{L}\right)\end{array}$ & $\begin{array}{l}(21) \\
(22)\end{array}$ & $\begin{array}{l}\text { Jiang et al. (2001) } \\
\text { Jiang et al. } \\
(2002 \mathrm{a}, \mathrm{b})\end{array}$ \\
\hline V & $\begin{array}{c}F_{g L}=\frac{\alpha_{g}}{\left(1-\alpha_{S}\right)}\left[A_{g}\left(\frac{\alpha_{S}}{1-\alpha_{g}}\right)^{2 / 3}+B_{g}\left(\frac{\alpha_{S}}{1-\alpha_{g}}\right)^{1 / 3}\left(u_{g}-u_{L}\right)\right] \\
F_{g S}=\frac{\alpha_{S}\left(1-\alpha_{S}\right)^{1.8}}{\left(1-\alpha_{g}\right) \alpha_{g}^{1.8}}\left[A_{g}\left(\frac{\alpha_{S}}{1-\alpha_{g}}\right)+B_{g} u_{g}\right] \\
F_{L S}=\alpha_{L}\left(\frac{\varepsilon-\alpha_{L}^{0}}{\alpha_{L}-\alpha_{L}^{0}}\right)^{2.43}\left(A_{L}+B_{L} u_{L}\right)\end{array}$ & (24) & $\begin{array}{l}\text { Jiang et al. } \\
(2002 a, b)\end{array}$ \\
\hline VI & $\begin{array}{l}F_{g S}=\frac{\alpha_{S}\left(1-\alpha_{S}\right)^{1.8}}{\left(1-\alpha_{g}\right) \alpha_{g}^{1.8}}\left[A_{g}\left(\frac{\alpha_{S}}{1-\alpha_{g}}\right)+B_{g} u_{g}\right] \\
F_{L S}=\frac{\alpha_{L}^{4}}{\left(1-\alpha_{S}\right)^{3}}\left(\frac{\varepsilon-\alpha_{L}^{0}}{\alpha_{L}-\alpha_{L}^{0}}\right)^{2.43}\left(A_{L}+B_{L} u_{L}\right)\end{array}$ & (27) & $\begin{array}{l}\text { Atta et al. }(2007 a, b) \\
\text { Atta et al. }(2010 a, b)\end{array}$ \\
\hline
\end{tabular}



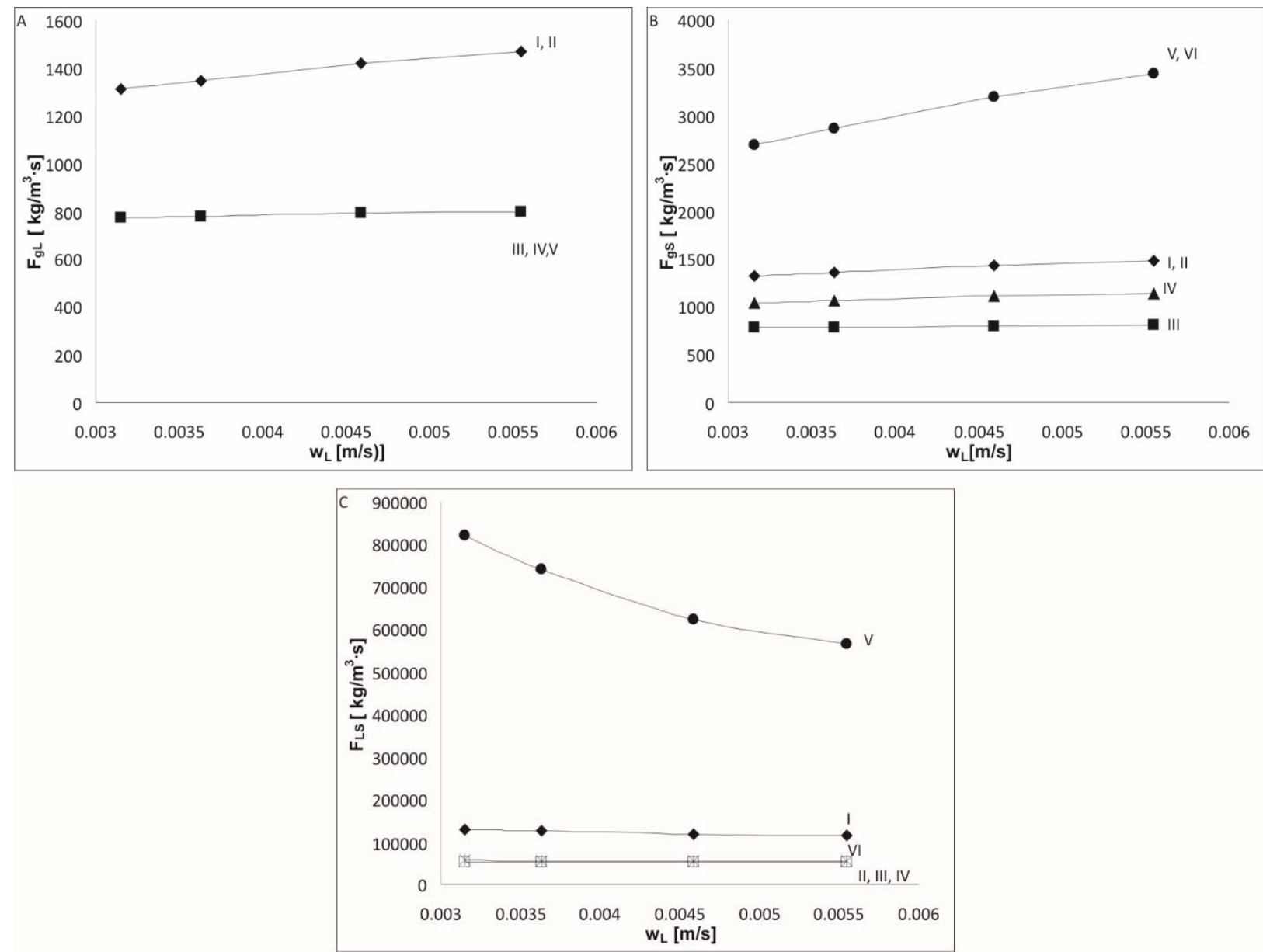

Fig. 1. Comparison of $F_{j k}$ values applied in computations by different authors (description the same as in Table 1); $\mathrm{w}_{\mathrm{g}}=0.25 \mathrm{~m} / \mathrm{s} ; \mathrm{A}-F_{g L}$ vs $w_{L} ; \mathrm{B}-F_{g S}$ vs $w_{L} ; \mathrm{C}-F_{L S}$ vs $w_{L}$;

\section{RESULTS AND DISCUSSION}

Computations determining the averaged holdup in the bed and the pressure drop were performed using commercial Fluent 6.1.22 software. Experimental data-base, obtained as a result of measurements for varying flow rates of both phases and for systems with various physicochemical properties, was the frame of reference for simulations.

Experiments were performed in a column $0.057 \mathrm{~m}$ in diameter filled with $1.375 \mathrm{~m}$ layer of glass spheres $0.003 \mathrm{~m}$ in diameter. Nitrogen was the gas phase, whereas water and glycerol solutions were the liquid phase. Physicochemical properties of tested solutions are listed in Table 2.

Table 2. Physicochemical properties of the solutions used in experiments $\left(21^{\circ} \mathrm{C}\right)$.

\begin{tabular}{|l|c|c|c|}
\hline \multicolumn{1}{|c|}{ Composition of the solutions } & $\rho, \mathrm{kg} / \mathrm{m}^{3}$ & $\mu \cdot 10^{3}, \mathrm{~Pa} \cdot \mathrm{s}$ & $\sigma \cdot 10^{3}, \mathrm{~N} / \mathrm{m}$ \\
\hline Water & 999.8 & 1.04 & 72.4 \\
\hline Solution of glycerol (30wt.\%) & 1072.2 & 2.5 & 72.0 \\
\hline Solution of glycerol (35wt.\%) & 1085.5 & 3 & 71.8 \\
\hline
\end{tabular}

The bed was flooded several times before each series of experiments so the values of hydrodynamic parameters were obtained for a prewetted bed $(f=1)$. A detailed description of the installation and experimental procedure was presented elsewhere (Janecki et al., 2014). 
Taking into account the results of simulations presented by Janecki et al. (2014) the values of Ergun constants equal to $E_{1}=180$ and $E_{2}=1.8$ as well as constant bed porosity $\left(D / d_{p}\right.$ used in our experiments exceeded the limiting value $D / d_{p}=18$ ) were applied in the computations.

Simulations were performed for all the experimental systems presented in Table 2 applying for each of them six sets of friction factors listed in Table 1.

In order to introduce a quantitative criterion for the evaluation and comparison of the computed results, the mean relative error as well as the standard deviation of the averaged holdup and the pressure drop with respect to the experimental values were determined for each set and listed in Table 3.

Table 3. Mean relative error $\left(e_{Y}\right)$ and standard deviation $\left(\sigma_{s t}\right)$ of the gas pressure drop and liquid holdup values obtained experimentally and calculated from CFD model applying in simulations the values of $F_{j k}$ from Table 1.

\begin{tabular}{|l|c|c|c|c|}
\hline \multirow{2}{*}{ Cases } & \multicolumn{2}{|c|}{$\Delta P, \mathrm{~Pa}$} & \multicolumn{2}{c|}{$\varepsilon_{L}$} \\
\cline { 2 - 5 } & $e_{Y}, \%$ & $\sigma_{s t}, \%$ & $e_{Y}, \%$ & $\sigma_{s t}, \%$ \\
\hline Case I & 16.61 & 15.93 & 6.76 & 2.67 \\
\hline Case II & 28.65 & 6.12 & 24.8 & 4.26 \\
\hline Case III & 49.57 & 4.18 & 19.4 & 4.53 \\
\hline Case IV & 43.21 & 4.75 & 20.22 & 4.37 \\
\hline Case V & 119.91 & 27.17 & 15.2 & 3.43 \\
\hline Case VI & 42.71 & 5.54 & 12.05 & 2.18 \\
\hline Modified Case V & 30.18 & 8.66 & 18.9 & 2.5 \\
\hline
\end{tabular}

Analysing the errors of hydrodynamic parameters listed in Table 3 one should distinguish a set of friction factors in Case I (Hamidipour et al., 2013, Janecki et al. (2014)) which exhibits the lowest errors and so approximates experimental values with the best agreement.

A modification of the friction factor $F_{L S}$ in Case II with respect to Case I caused an increase of both errors worsening the approximation of experimental values.

Cases III, IV and VI present rather poor agreement with experimental values, as the errors of pressure drop are situated in the range of $40 \%-50 \%$ and those of liquid holdup around $12 \%-25 \%$. A large error of pressure drop in Case V is striking and quite inexplicable. Comparing the $F_{L S}$ friction factors from Case V (Eq. 25) and Case VI (Eq. 27) which should present quantities taken from the relative permeability model (Saez and Carbonell (1985)) one can suspect a typographical error in Eq. (25). Therefore it was decided to repeat the calculations of Case V exchanging Eq. (25) with Eq. (27) which caused a decrease of the pressure drop error from $119.91 \%$ to $30.18 \%$ (modified Case V in Table 3).

The differences between the values of the hydrodynamic parameters estimated for six sets of friction factors (Table 3) can be partially explained by the differences between the friction factors presented in Fig.1. Particularly, the difference between the values of the friction factors $F_{g L}$ determined by Attou et al. (1999) (Case I) and modified by Jiang et al. (2002a, b) (Case III). Similarly, the $F_{g S}$ friction factors of the permeability model (Case VI) differ significantly from the friction factors of other cases.

Experimental data as well as the results of CFD simulations are illustrated in diagrams (Fig. 2) presenting, for three systems and $w_{g}=0.25 \mathrm{~m} / \mathrm{s}$, hydrodynamic parameters as a function of superficial liquid velocities. 

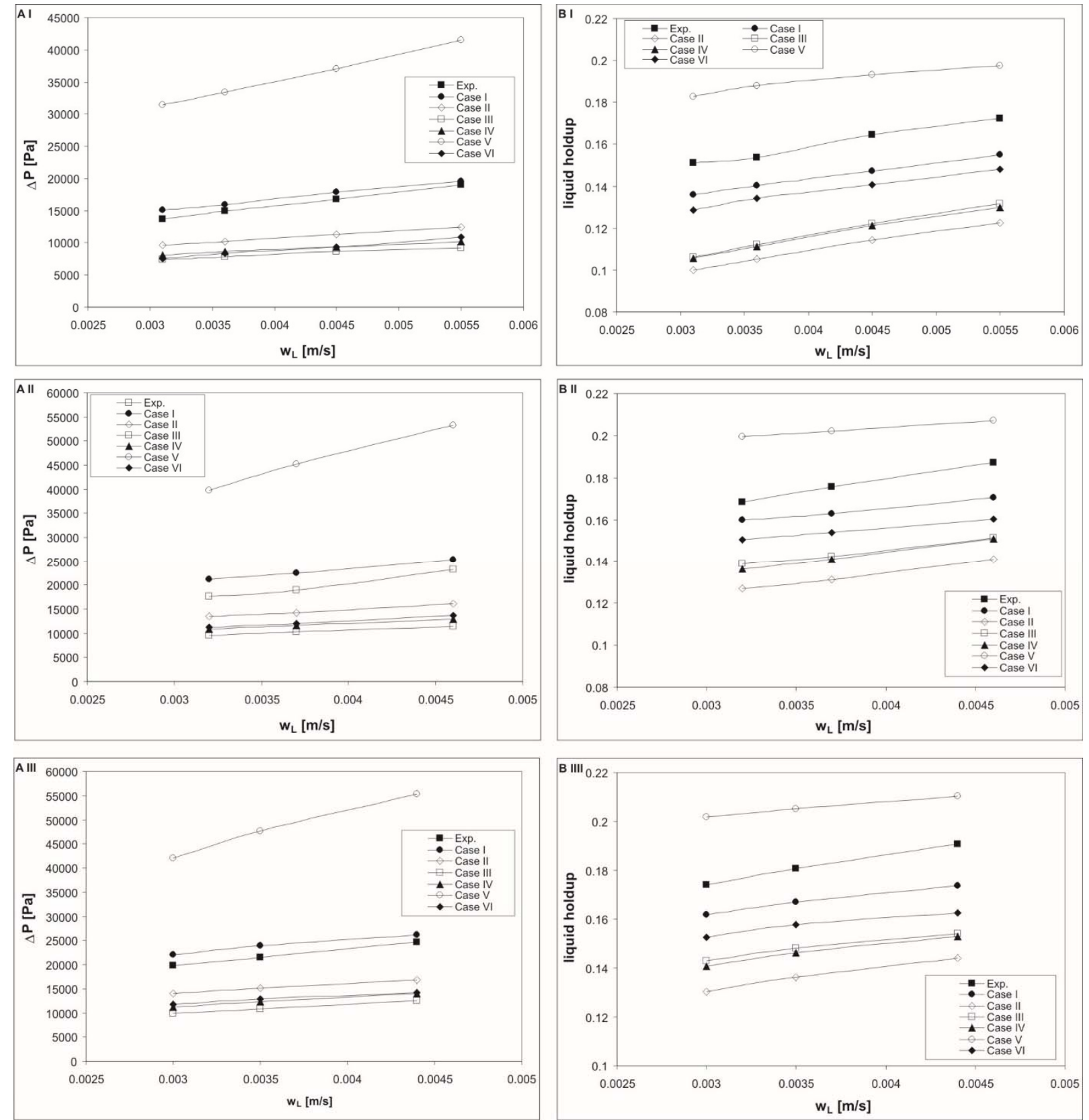

Fig. 2. Pressure drop (A) and total liquid holdup (B) vs superficial liquid velocity: comparison of theoretical predictions obtained using the values of $F_{j k}$ from Table 1 with experimental data (Janecki et al., 2014); $w_{g}=0.25 \mathrm{~m} / \mathrm{s}$. Systems: I - nitrogen-water; II - nitrogen-glycerol (30wt.\%); III - nitrogen-glycerol (35wt.\%).

Additionally, special diagrams (parity plots) were prepared to compare computed results with experimental data (Fig. 3). The plots illustrate clearly the discrepancies between calculated and experimental values for each set of friction factors.

It can be noted, that except for Case I which approximates experimental values very well, other Cases underestimate computed values with respect to experimental data pressure drop and mean liquid holdup. 

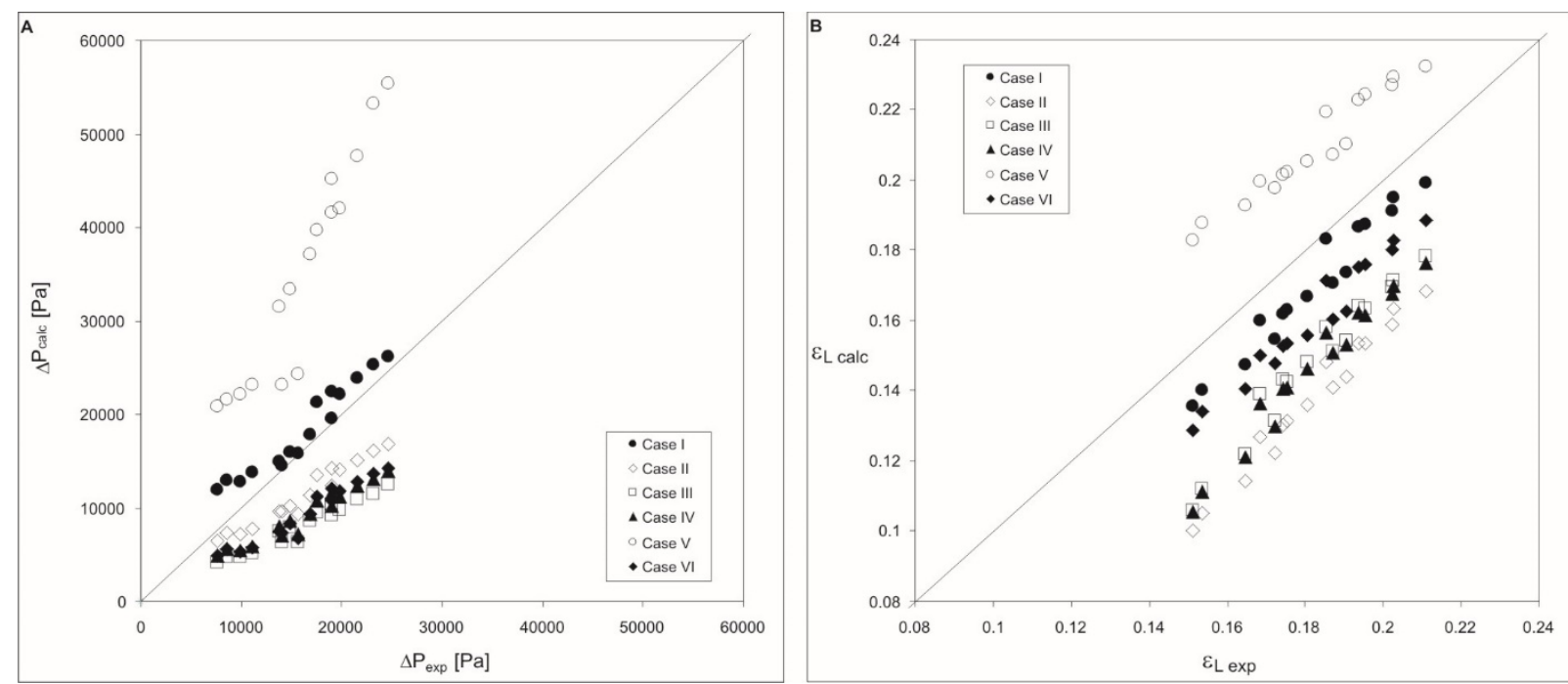

Fig. 3. Pressure drop (A) and total liquid holdup (B) experimentally and calculated using in CFD model the values of $F_{j k}$ from Table 1 .

\section{CONLUSIONS}

In order to investigate the parametric sensitivity of a CFD, model simulations were performed for all experimental systems presented in Table 2 applying for each of them six sets (Cases) of friction factors listed in Table 1. The mean relative error as well as standard deviation of experimental and computed values of the pressure drop and average liquid holdup were used as the validation criteria of the model. Simulations indicate clearly that the classical equations of Attou et al. (1999), defining the friction factors $F_{j k}$ approximate the experimental values of the hydrodynamic parameters with the best agreement. Taking this into account one can recommend to apply these equations in the momentum balances of TBRs. As the computed errors of other Cases are situated in the range of $40-50 \%$ for the pressure drop and in the range $12-25 \%$ for the liquid holdup, the modified form of equations defining $F_{j k}$ does not seem to be satisfactory.

\section{SYMBOLS}

D column diameter, $\mathrm{m}$

$d_{p} \quad$ particle diameter, $\mathrm{m}$

$e_{y}=\frac{1}{N} \sum_{i=1}^{N}\left|\frac{Y_{\text {exp }, i}-Y_{\text {calc }, i}}{Y_{\text {exp }, i}}\right| \quad$ average relative error, \%

$E_{1}, E_{2} \quad$ Ergun constants

$f \quad$ wetting efficiency of the bed

$F_{j k} \quad$ momentum exchange coefficients between phases $j$ and $k, \mathrm{~kg} /\left(\mathrm{m}^{3} \cdot \mathrm{s}\right)$

g acceleration due to gravity, $\mathrm{m} / \mathrm{s}^{2}$

$\bar{u} \quad$ interstitial velocity, $\mathrm{m} / \mathrm{s}$

w superficial velocity, $\mathrm{m} / \mathrm{s}$

Greek symbols

$\alpha \quad$ volume fraction

$\varepsilon \quad$ porosity of the bed

$\varepsilon_{L} \quad$ liquid holdup 


$\begin{array}{ll}\eta & \text { dynamic viscosity, Pa.s } \\ \rho & \text { density, } \mathrm{kg} / \mathrm{m}^{3} \\ \sigma & \text { surface tension, } \mathrm{N} / \mathrm{m} \\ \bar{\tau} & \text { stress tensor, } \mathrm{N} / \mathrm{m}^{2} \\ \delta_{s t}=\sqrt{\frac{1}{N} \sum_{i=1}^{N}\left(\left|\frac{Y_{\text {exp }, i}-Y_{\text {calc }, i} \mid}{Y_{\text {exp }, i}}\right|-e_{y}\right)^{2}} \quad \text { standard deviation, \% }\end{array}$

$\begin{array}{ll}\text { Subscripts } & \\ d & \text { dynamic } \\ \text { calc } & \text { calculated } \\ \exp & \text { experimental } \\ g, L, s & \text { gas, liquid, solid phases } \\ j & \text { phase other than } k \\ k & k^{\text {th }} \text { phase }\end{array}$

\section{REFERENCES}

Al-Dahhan M.H., Dudukovic M.P., 1994. Pressure drop and liquid holdup in high pressure trickle-bed reactors. Chem. Eng. Sci., 49, 5681-5698. DOI: 10.1016/0009-2509(94)00315-7.

Al-Dahhan M.H., Larachi F., Dudukovic M.P., Laurent A., 1997. High pressure trickle-bed reactors: A review. Ind. Eng. Chem. Res., 36, 3292-3314. DOI: 10.1021/ie9700829.

Atta A., Shantanu R., Nigam K.D.P., 2007a. Prediction of pressure drop and liquid holdup in trickle bed reactor using relative permeability concept in CFD. Chem. Eng. Sci., 62, 5870-5879. DOI: 10.1016/j.ces.2007.06.008.

Atta A., Shantanu R., Nigam K.D.P., 2007b. Investigation of liquid maldistribution in trickle bed reactor using porous media concept in CFD. Chem. Eng. Sci., 62, 7033-7044. DOI: 10.1016/j.ces.2007.07.069.

Attou A., Boyer C., Ferschneider G., 1999. Modeling of the hydrodynamics of the cocurrent gas-liquid trickle flow through a trickle-bed reactor. Chem. Eng. Sci. 54. 785-802, DOI: 10.1016/s0009-2509(98)00285-1.

Bartelmus G., Janecki D., 2003. Hydrodynamics of a cocurrent downflow of gas and foaming liquid through the packed bed. Part II. Liquid holdup and gas pressure drop. Chem. Eng. Process., 42, 993-1005. DOI: 10.1016/S0255-2701(03)00005-9.

Burghardt A., 2014 Eulerian three-phase flow model applied to trickle-bed reactors. Chem. Process Eng., 35, 75-96. DOI: 10.2478/cpe-2014-0006.

Burghardt A., Bartelmus G., Janecki D., Szlemp A., 2002. Hydrodynamics of a three-phase fixed-bed reactor operating in the pulsing flow regime at an elevated pressure. Chem. Eng. Sci., 57, 4855-4863. DOI: 10.1016/s0009-2509(02)00279-8.

Burghardt A., Bartelmus G., Szlemp A., Janecki D., 2005. Analiza matematycznych kryteriów zmiany reżimów hydrodynamicznych w reaktorach trójfazowych. Chem. Process Eng., 26, 259-279.

Charpentier J.C., Favier M., 1975. Some liquid holdup experimental data in trickle-bed reactors for foaming and nonfoaming hydrocarbons. AJChE J., 21, 1213-1218. DOI: 10.1002/aic.690210626.

Gunjal P.R., Kashid M.N., Ranade V.V., Chaudhari R.V., 2005. Hydrodynamics of trickle-bed reactors: Experiments and CFD modeling. Ind. Eng. Chem. Res., 44, 6278-6294. DOI: 10.1021/ie0491037.

Gunjal P.R., Ranade V.V., 2007. Modeling of laboratory and commercial scale hydro-processing reactors using CFD. Chem. Eng. Sci., 62. 5512-5526. DOI: 10.1016/j.ces.2007.01.078.

Hamidipour M., Chen J., Larachi F., 2013. CFD study and experimental validation of trickle bed hydrodynamics under gas, liquid and gas/liquid alternating cyclic operations. Chem. Eng. Sci., 89, 158-170. DOI: 10.1016/j.ces.2012.11.041.

Holub R.A., Duduković P.A., Ramachandran P.A., 1992. A phenomenological model for pressure drop, liquid holdup and flow regime transition in gas-liquid trickle flow. Chem. Eng. Sci., 47, 2343-2348. DOI: 10.1016/0009-2509(92)87058-x. 
Janecki D., Burghardt A., Bartelmus G., 2007. The hydrodynamics of cocurrent gas and liquid flow through a packed bed. Modelling by means of computational fluid dynamics (CFD). Chem. Process Eng., 28, 361-37.

Janecki D., Burghardt A., Bartelmus G., 2014. Influence of the porosity profile and sets of Ergun constants on the main hydrodynamic parameters in the trickle-bed reactors. Chem. Eng. J., 237, 176-188. DOI: 10.1016/j.cej.2013.09.102.

Jiang Y., Khadilkar M.R., Al-Dahhan M.H., Dudukovic M.P., 2001. CFD modelling of multiphase flow distribution in catalytic packed bed reactors: scale down issues. Catal. Today, 66, 209-218. DOI: 10.1016/s09205861(00)00642-8.

Jiang Y., Khadilkar M.R., Al-Dahhan M.H., Dudukovic M.P., 2002a. CFD of multiphase flow in packed-bed reactors: I. K-fluid modelling issues. AIChE J., 48, 701-715. DOI: 10.1002/aic.690480406.

Jiang Y., Khadilkar M.R., Al-Dahhan M.H., Dudukovic M.P., 2002b. CFD of multiphase flow in packed-bed reactors: II. Results and applications. AIChE J., 48, 716-730. DOI: 10.1002/aic.690480407.

Kuzeljevic Z.V., Dudukovic M.P., 2012. Computational modeling of trickle bed reactors. Ind. Eng. Chem. Res., 51, 1663-1671. DOI: 10.1021/ie2007449.

Lappalainen K., Manninen M., Alopaeus V., 2009. CFD modeling of radial spreading of flow in trickle-bed reactors due to mechanical and capillary dispersion. Chem. Eng. Sci., 64, 207-218. DOI: 10.1016/j.ces.2008.10.009.

Larachi F., Laurent A., Midoux N., Wild G., 1991. Experimental study of a trickle-bed reactor operating at high pressure: Two phase pressure drop and liquid saturation. Chem. Eng. Sci., 46, 1233-1246. DOI: 10.1016/00092509(91)85051-x.

Midoux N., Favier M., Charpentier J.C., 1976. Flow pattern, pressure loss and liquid holdup data in gas-liquid downflow packed beds with foaming and nonfoaming hydrocarbons. J. Chem. Eng. Japan, 9, 350-356. DOI: $10.1252 /$ jcej. 9.350 .

Mills P.L., Dudukovic M.P., 1981. Evaluation of liquid-solid contacting in trickle-bed reactors by tracer methods. AIChE J., 27, 893-904. DOI: 10.1002/aic.690270604.

Saez A.E., Carbonell R.G., 1985. Hydrodynamic parameters for gas-liquid cocurrent flow in packed beds. AIChE $J ., 31,52-62$. DOI: 10.1002/aic.690310105.

Sai P.S.T., Varma Y.B.G., 1987. Pressure drop in gas-liquid downflow through packed beds, AIChE J., 33, 20272036. DOI: $10.1002 /$ aic.690331213.

Saroha A.K., Nigam K.D.P., 1996. Trickle bed reactors. Rev. Chem. Eng., 12, 207-347. DOI: 10.1515/REVCE.1996.12.3-4.207.

Specchia V., Baldi G., 1977. Pressure drop and liquid hold-up for two phase cocurrent flow in packed beds. Chem. Eng. Sci., 32, 515-532. DOI: 10.1016/0009-2509(77)87008-5.

Szlemp A., Bartelmus G., Janecki D., 2001. Hydrodynamics of a co-current three-phase solid-bed reactor for foaming systems. Chem. Eng. Sci., 56, 1111-1116. DOI:10.1016/S0009-2509(00)00328-6.

Wammes W.J.A., Middelkamp J., Huisman W.J., deBaas C.M., Westerterp K.R., 1991. Hydrodynamics in a cocurrent gas-liquid trickle bed at elevated pressures. AIChE J., 37, 1849-1861. DOI: 10.1002/aic.690371210.

Received 24 June 2015

Received in revised form 27 January 2016

Accepted 28 January 2016 